\title{
Central Asia earthquake catalogue from ancient time to 2009
}

\author{
Natalya N. Mikhailova ${ }^{1,{ }^{\star}}$, Aidyn S. Mukambayev ${ }^{1}$, Irina L. Aristova ${ }^{1}$, Galina Kulikova ${ }^{1}$, \\ Shahid Ullah ${ }^{2}$, Marco Pilz ${ }^{2}$, Dino Bindi ${ }^{2}$ \\ ${ }^{1}$ Institute of Geophysical Researches, Committee of Atomic Energy of the Republic of Kazakhstan, Almaty, Kazakhstan \\ ${ }^{2}$ Helmholtz Center Potsdam - German Research Center for Geosciences, Potsdam, Germany
}

\author{
Article history \\ Received October 12, 2014; accepted January 12, 2015. \\ Subject classification: \\ Seismology, Seismic catalog, Hazard.
}

\begin{abstract}
In this work, we present the seismic catalogue compiled for Central Asia (Kazakhstan, Kyrgyzstan, Tajikistan, Uzbekistan and Turkmenistan) in the framework of the Earthquake Model Central Asia (EMCA) project. The catalogue from 2000 B.C. to 2009 A.D. is composed by 33,034 earthquakes in the MLH magnitude (magnitude by surface waves on horizontal components widely used in practice of the former USSR countries) range from 1.5 to 8.3. The catalogue includes both macroseimic and instrumental constrained data, with about 32,793 earthquake after 1900 A.D. The main sources and procedure used to compile the catalogues are discussed, and the comparison with the ISC-GEM catalogue presented. Magnitude of completeness analysis shows that the catalogue is complete down to magnitude 4 from 1959 and to magnitude 7 from 1873, whereas the obtained regional $b$ value is 0.805 .
\end{abstract}

\section{Introduction}

The aim of the Earthquake Model Central Asia (EMCA) project (http: / / www.emca-gem.org) is the development of new regional hazard and risk models for Kazakhstan, Kyrgyzstan, Tajikistan, Uzbekistan and Turkmenistan. In order to build these new models, input data for hazard and risk assessments have to be collected and revised. The quality control is of particular relevance for parameters spanning an extended period, from 2000 B.C. to recent years, since very heterogeneous data sources and procedures were used to create them. Such an example is provided by the seismic catalogue compiled for seismic hazard assessment, which includes information about origin time, location, and magnitude extracted from both historical and instrumental data. Until the collapse of the Soviet Union (USSR) in 1990, seismic observations, data processing, catalogues compilation, and creation of seismic zoning maps was coordinated for all USSR countries using same methods and approaches. An example of results from the USSR seismologists effort was the specialized earthquake catalogue of North Eurasia from ancient time to 1990 published under the coordination of Kondorskaya and Ulomov [1996], that was used for calculation of a set of seismic hazard zoning maps of USSR [Ulomov and Shyumilina 2000].

The collapse of the Soviet Union in 1990 had a strong impact on the scientific practice in Central Asia. The application of unified approaches among the countries was interrupted as well as the data exchange and the management of cross-border networks. The number of operating seismic stations decreased sharply and the compilation of operative bulletins for Central Asia was interrupted. Furthermore, many qualified specialists left their centers. Under these conditions, the catalogues homogeneity for the whole territory was also interrupted and the restoration of seismic databases since 1991 is problematic.

A recent attempt to perform a cross-border risk assessment for Central Asia has been performed within the ISTC-CASRI project [Seismic Risk Assessment in Central Asia 2009]. CASRI had been implemented between 2006-2009 with participation of Kyrgyzstan, Kazakhstan, Uzbekistan and Tajikistan. Turkmenistan did not participate in the Project. One of the main products released by CASRI was a unified catalogue including earthquakes from 2000 B.C. to 2005 A.D. with MLH magnitude $\geq 4.5$. The activities, coordinated by the Data Center of the Institute of Geophysical Researches (IGR) of Kazakhstan (KNDC), confirmed the difficulties in compiling a unified catalogue for central Asia after 1990 due to the strong heterogeneity in the standards implemented by the different national seismological centers.

The EMCA catalogue presented in this study was built at IGR starting from the CASRI experience. The catalogue was extended both spatially, by including the 
territory of Turkmenistan, and temporally, by updating the catalogue to 2009. The entries of the catalogue were revised exploiting also recent scientific works and catalogues, like the ISC-GEM one [Storchak et al. 2015]. The aim of this work is to present an overview about the sources used and the activities carried out to compile the EMCA seismic catalogue.

\section{Data sources}

Different sources were considered for earthquakes that occurred before or after 1990. In the former case, the main source was the Specialized catalogue of Northern Eurasia earthquakes [Kondorskaya and Ulomov 1996]. The Central Asia earthquake catalogue until 1990 is very heterogeneous. The entries selected for the region of five Central Asia countries of the former USSR were revised removing some blasts and nuclear explosions and adding some events and additional parameters obtained from different regional catalogues. All earthquakes until 1900 were determined by macroseismic data only. Instrumental observations in Central Asia countries started in 1901 when the first seismic station was installed in Tashkent. After that several seismic stations were installed in large cities: Samarkand (1925), Frunze (nowdays known as Bishkek) (1927), Alma-Ata (Almaty) (1927), Chimkent (1932), Semipalatinsk (1934). Thus, the first seismic network on the territory of Central Asia was established. The next stage in seismic observations development was connected with disastrous Ashkhabad earthquake of 1948, M=7.3 resulted in tens of thousands casualties. For short period of time, the number of stations increased almost threefold. For the first time, in Moscow, the Coordination Centre was established to join the efforts of all seismic services of the USSR territory. Rapid development of seismic networks was in 1970-1980. It is obvious that the larger was the number of observation stations the smaller was minimum magnitude recorded from the

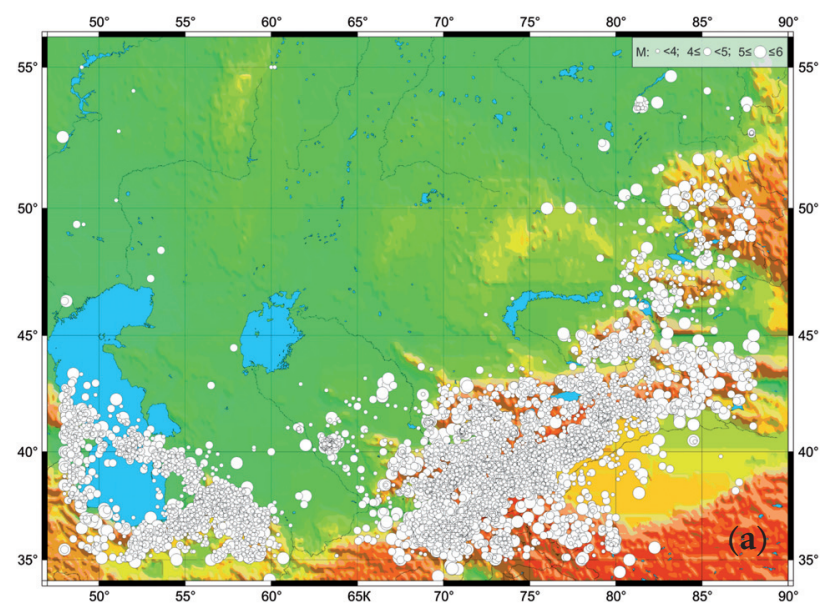

earthquakes, and the more accurate was the determined source location. Since 1964 until the Soviet Union collapse all seismic observations and data processing were conducted within Common Network of Seismic Observations using the same regulations and under methodic coordination. The earthquake catalogues for the whole territory of the Soviet Union including Central Asia were published annually [Earthquakes in the USSR 1961-1991]. These catalogues were the base of the Specialized Earthquakes Catalogue [Kondorskaya and Ulomov 1996]. The final catalogue compiled for EMCA catalogue includes 10,542 events occurred from 2000 B.C. to 1990 A.D. The minimum magnitude included in the catalogue for events occurred before and after 1960 is 4.5 and 3.5, respectively. The events distribution of the EMCA catalogue is shown in Figure 1.

For the compilation of the catalogue after 1990, different sources were considered, as outlined in Figure 2. In particular, information from both international and regional data centers was used. The main international centers considered are:

- the International Seismological Centre (ISC) bulletin (http:/ / www.isc.ac.uk/iscbulletin/search/);

- Reviewed Event Bulletin of the International Data Center of the Comprehensive Test-Ban Treaty Organization (REB; http:/ / www.ctbto.org/verificationregime/the-international-data-centre/);

- the bulletin of the National Earthquake Information Center (NEIC) of the U.S. Geological Survey (http:/ / earthquake.usgs.gov/regional/neic/neic_bul letins.php).

The main regional sources are:

- the earthquake catalogues compiled for Kazakhstan territory by the seismological experience-methodical expedition (SEME) MES-RK (http: / / www. some.kz);

- seismological bulletins compiled by the Data Center of IGR (Kazakhstan National Data Center

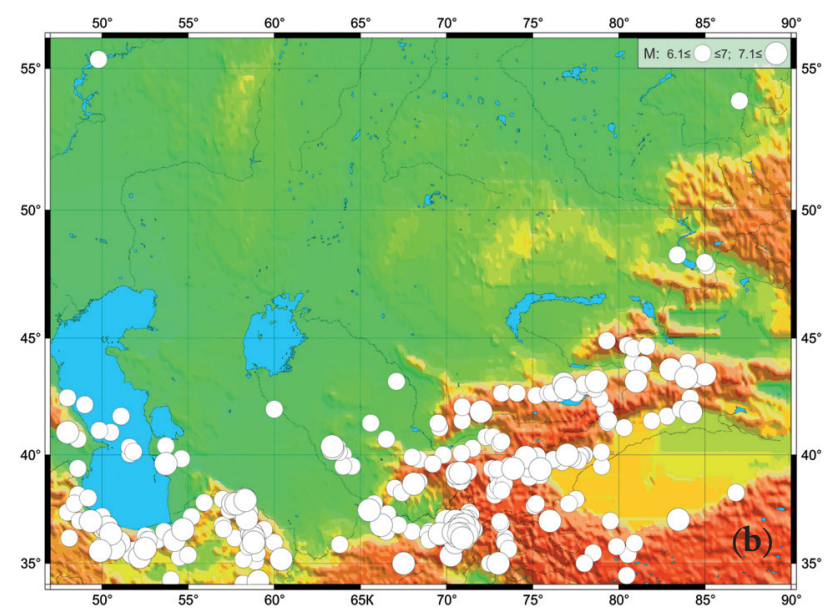

Figure 1. The map of earthquakes epicenters by the Central Asia catalogue EMCA until 1991. (a) with magnitude $\leq 6.0$; (b) with magnitude $\geq 6.1$. 


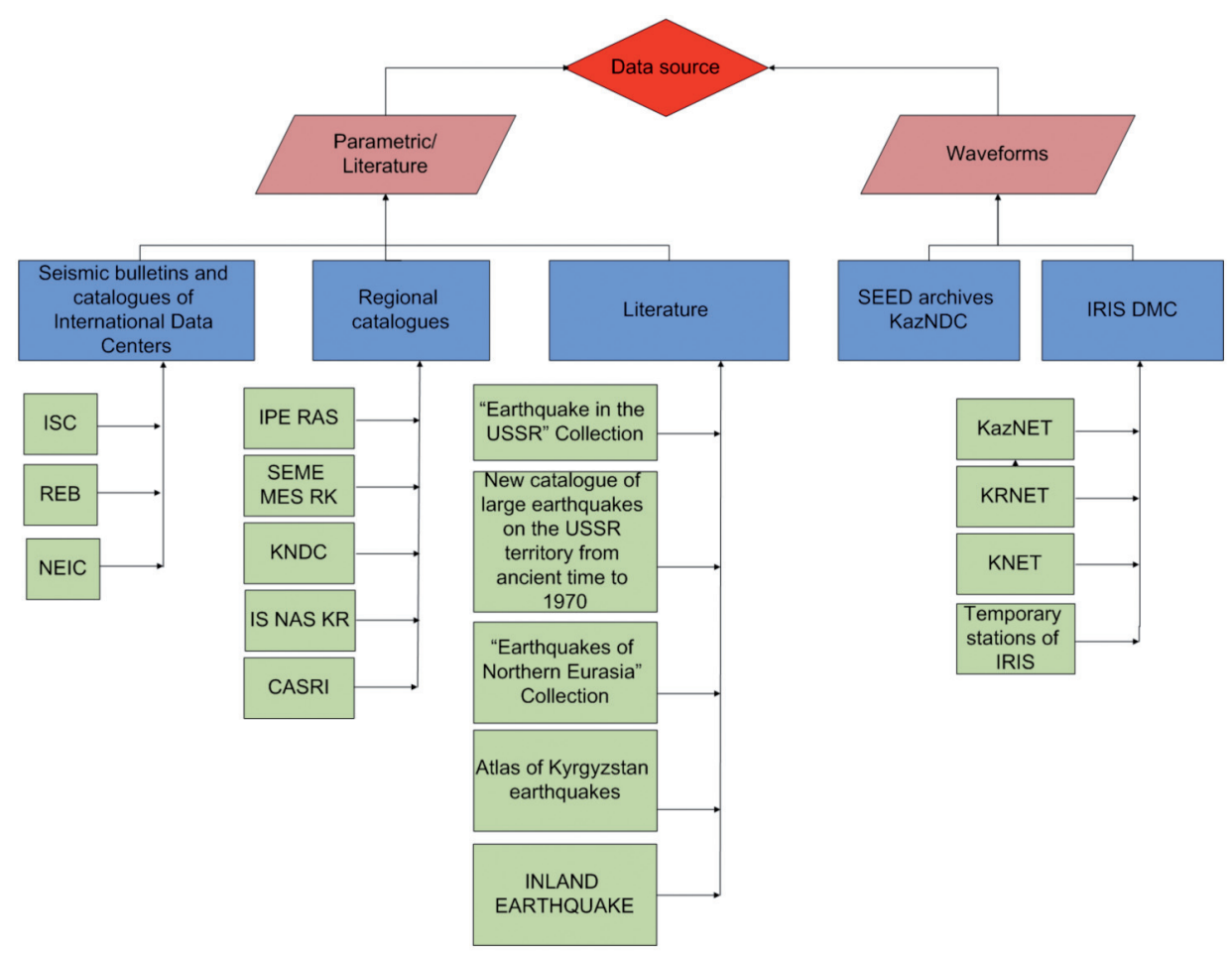

Figure 2. The sources used to compile the EMCA catalogue.

KNDC) (http: / / www.kndc.kz/index.php/en/seismicbulletins/interactive-bulletin);

- for eastern (from longitude $80^{\circ}$ ) and northern part (from latitude $46^{\circ}$ ) of the territory, the published catalogues of Altay-Sayan expedition RAS were used [Earthquakes in the USSR 1961-1991, Earthquakes of Northern Eurasia 1991-2007];

- Earthquake catalogues of the Institute of Seismology of Kyrgyz Republic (http: / / www.seismo.kg);

- CASRI catalogue [Seismic Risk Assessment in Central Asia 2009].

Information from scientific publications was also used. Examples are the yearly summary collection of bulletin "Earthquakes in the USSR" and the annual collection "Earthquakes of North Eurasia" [Earthquakes in the USSR 1961-1991, Earthquakes of Northern Eurasia 1991-2007]. A catalogue published in China as a result of joint work of seismologists from different Central Asia countries was also considered [Inland Earthquake 1997]. Finally, information about significant earthquakes investigated in scientific articles was also collected.

To solve controversial issues (e.g. multiple earthquake locations; identification of false earthquake; discrimination between earthquake and explosions), original waveform data were also analyzed. Seismograms were collected from different regional and international data centers, such as the IGR in Kazakhstan; the KNET network near Bishkek [Bragin 2007]; the Kyrgyz national network KRNET; the Kazak national network KazNet; the IRIS in US [Consortium of the USA Universities].

To solve inconsistences among different sources, a hierarchical decision scheme was applied. For Northern Tien Shan territory in the south and south-east of Kazakhstan, where large amount of SEME MES-RK stations is concentrated (Figure 5), priority was given to the solutions provided by SEME MES-RK. For earthquakes occurred in Kyrgyzstan, the solutions provided by EMSE KR was considered. For other regions, the solutions from ISC and KNDC were considered. During the compilation, special attention was paid to exclude explosions which, alone in Kazakhstan, are of the order of several thousand per year.

Since the ISC catalogue includes a large number of earthquakes in Central Asia (about 13,000), it was used as reference for drawing the first draft of the EMCA catalogue. Figure 3 shows the number of events per year in Central Asia included in the NEIC and ISC bulletins. This is not surprising considering that the ISC collects and integrates bulletins from global and local/ regional agencies (http: / / www.isc.uk/iscbulletin/ agencies). Figure 4 shows the variation of the minimum and representative body wave magnitude $\mathrm{mb}$ for the ISC catalogue. The representative magnitude (i.e. the smallest $\mathrm{mb}$ recorded constantly and included into seismic bulletins) was estimated by the Data Center of IGR basing on yearly distribution of events by magnitudes. The sharp decrease of the minimum mb values after 2004 occurs because Data Center of IGR (KNDC) started to submit data to the ISC. During recent years, the representative magnitude for the whole territory has not been changed and it is close to 3.5. Body waves magnitude, $\mathrm{mb}$, is considered in Figure 4 because it is 


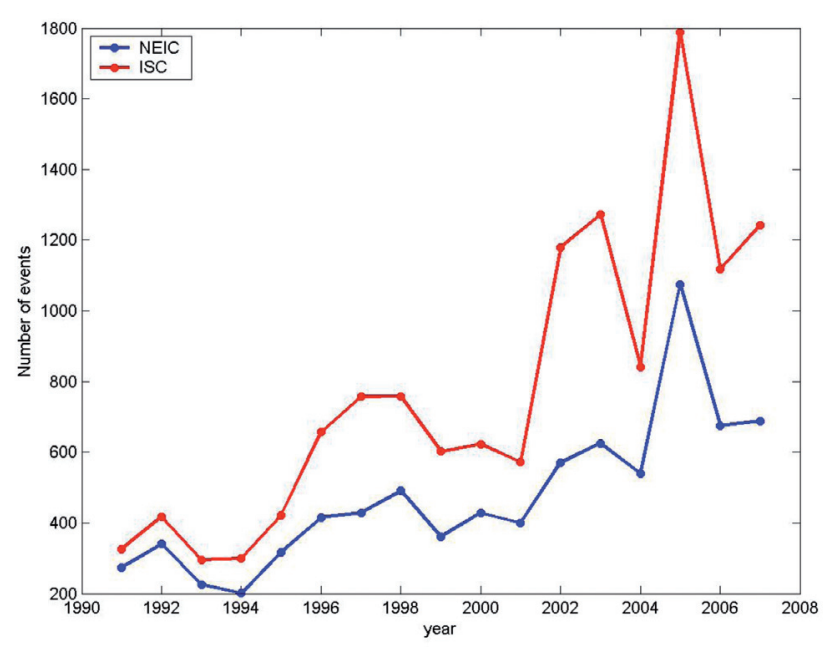

Figure 3. Changing of total amount of events by years for Central Asia territory in NEIC and ISC catalogues.

impossible to determine the surface waves magnitude (like MLH) for small near earthquakes as these waves are absent in earthquake records. Sharp decrease of minimum magnitude of earthquakes (to $m b=1$ ) is due to putting into operation of new modern high-sensitive seismic arrays installed in 2000-2006 on the territory of Kazakhstan. It is impossible to obtain this level of sensitivity for the whole territory of Kazakhstan and Central Asia. Thus, there is a quite large gap reaching about 2.5 magnitude units between representative magnitude $\mathrm{mb}$ and minimum recorded.

The seismic bulletins compiled in central Asia contain a set of energy and magnitude characteristics of earthquakes measured by different scales. Most often, at different periods the following types of magnitudes were determined - Ml, mB, mb, MPVA, MLH, MLV, Ms, Mw and energy class $K$ [Rautian 1960, Rautian 1964, Mikhailova and Neverova 1986, Rautian and Khalturin

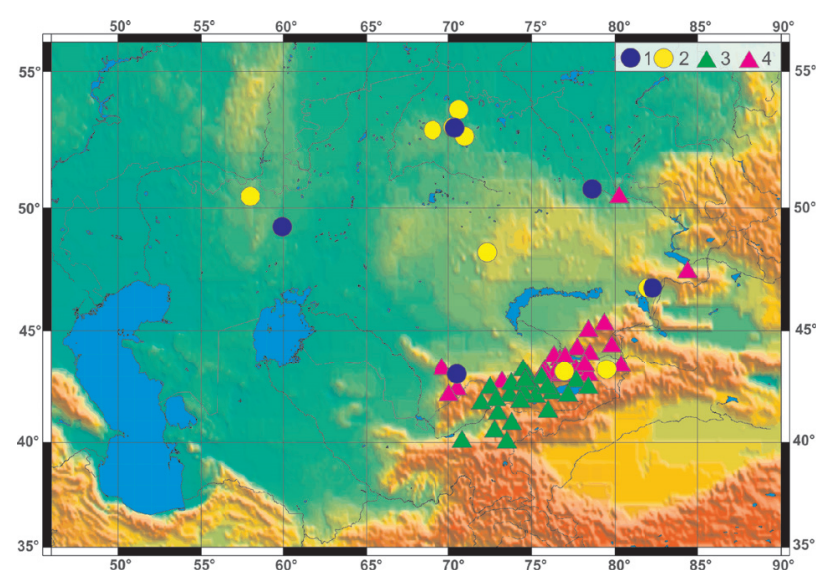

Figure 5. Map of the seismic stations used to address inconsistencies in the sources considered to compile EMCA catalogue between 1991 and 2009 A.D. See text for details. The legend reports: (1) seismic arrays of the IGR; (2) three-component stations of the IGR; (3) three-component stations of KNET and EMSE networks of Kyrgyzstan; (4) three-component stations of SEME MES-RK.

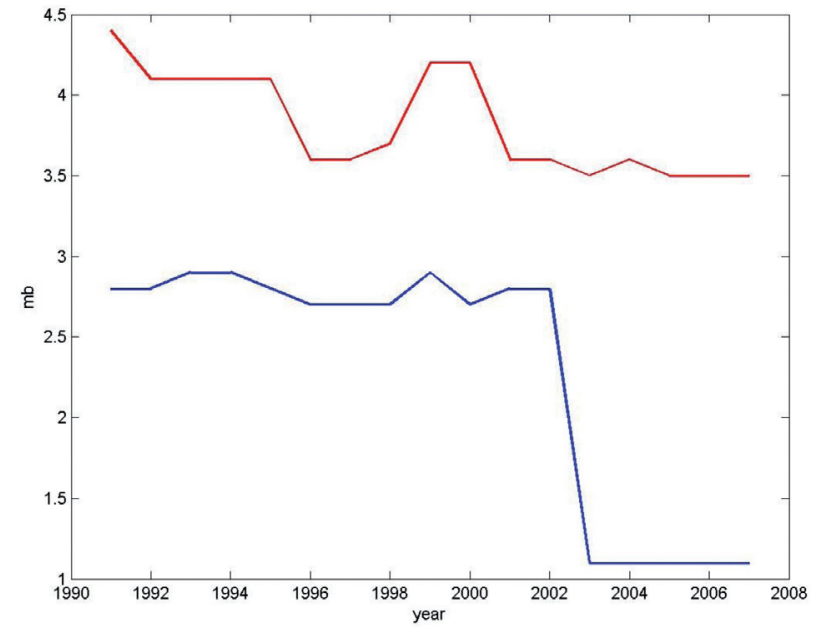

Figure 4. Changing of values of minimum (blue) and representative (red) magnitudes in the ISC catalogue for Central Asia territory.

1994, Bormann 2002, Rautian et al. 2007]. For earthquakes happened before instrumental period the magnitudes were measured by analysis of macroseismic data determined by isoseismal maps. These macroseismic magnitudes were calibrated by values of surface-waves magnitude MLH. This large number of magnitudes is due to application of different scales, waves types, instrument features of the global and regional networks, application of different calibration curves in different periods of time. For joint application of catalogue data in different tasks, various magnitudes were deduced to MLH magnitude value, close to Ms values. The MLH magnitude was chosen as a base one as, first, namely this magnitude was measured for the most of large earthquakes on instrumental period, second, macroseismic magnitude of earthquakes happened before instrumental period is based on it. It is also important that MLH magnitude is used for characteristics of seismic generating zones in the current maps of seismic zoning of Central Asia countries.

The final EMCA catalogue contains 33,034 earthquakes, 32,793 of which occurred after 1900. Table 1 shows the header of the catalogue along with two entries. Note that in addition to instrumental characteristics, the catalogue also contains some macroseismic information. This is the shake intensity in the epicenter $\left(\mathrm{I}_{0}\right)$, number of victims after large earthquakes, names of significant earthquakes. The distribution of the events with time, starting from 1900, is shown in the top panel of Figure 6 while the MLH distribution is shown in the bottom panel. Finally, the distribution of the epicenters for magnitude larger than 5 is shown in Figure 7.

\section{Comparison with the ISC-GEM catalogue}

The regional data were compared with global catalogue data compiled under GEM Project ("Global earthquake Model") [Storchak et al. 2015]. The cata- 


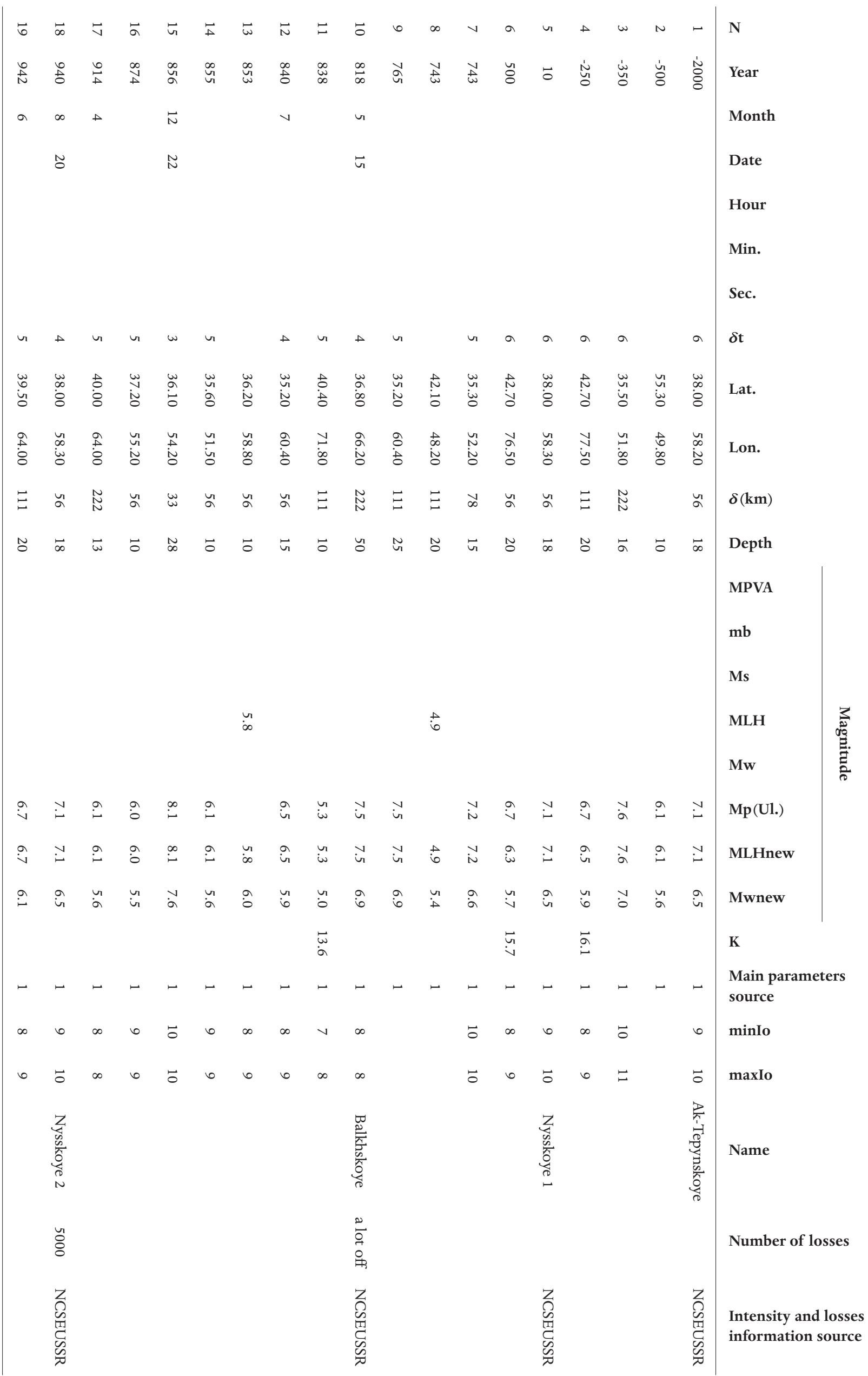




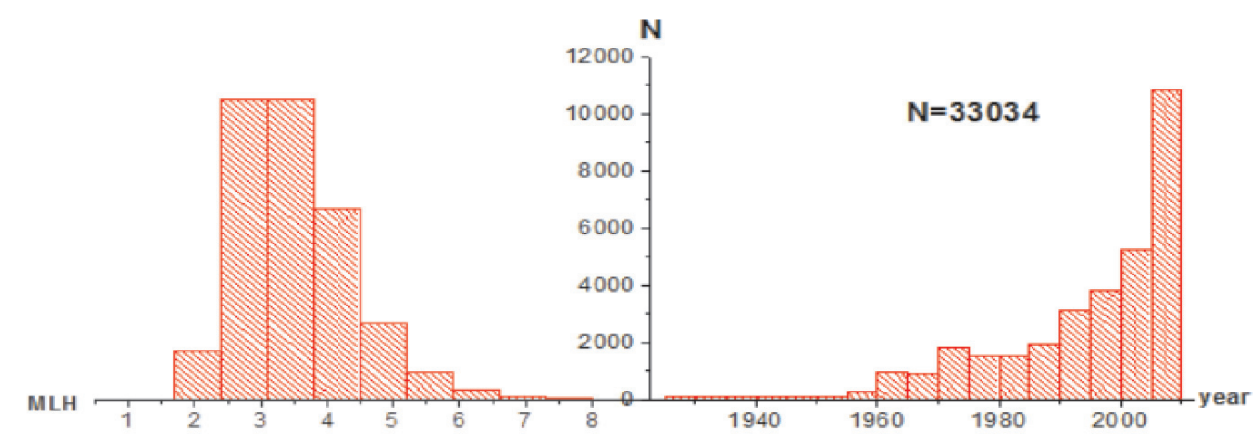

Figure 6. Right: distribution of earthquakes by years in the EMCA catalogue. Left: distribution of earthquakes by MLH magnitude.

logue, available on the ISC web-site (http:/ / www.isc. ac.uk), consists of about 20,000 instrumentally recorded medium and large earthquakes occurred from 1900 to 2009. The hypocenters of all events in the ISC-GEM catalogue were relocated using unified and accurate location procedures and depth determination technique [Bondár et al. 2015]. Different magnitude threshold values were considered for different time periods: for the period 1900-1917, the threshold magnitude is $\mathrm{Ms}=7.5$ for the whole world, and $\mathrm{Ms}=6.5$ for shallow earthquakes in stable continental regions; for the period 1918-1959, the threshold is $\mathrm{Ms}=6.25$; for $1960-2009$, the threshold is $\mathrm{Ms}=5.5$.

A geographical extraction of ISC-GEM for Central Asia was compared with EMCA and 20 events, located near the borders of the investigated region, were added to EMCA catalogue. The comparison between the hypocentral locations showed that for 309 over 329 common events, the distance between two locations was less than $40 \mathrm{~km}$. For 20 earthquakes (Figure 8), the discrepancy in locations was between 40 to $340 \mathrm{~km}$. The information for these events was re-evaluated and corrections applied. An example of earthquake showing a significant discrepancy is the 1911, Kemin earthquake. It occurred near Verniy city (former name of Almaty) and resulted in large destructions and victims.

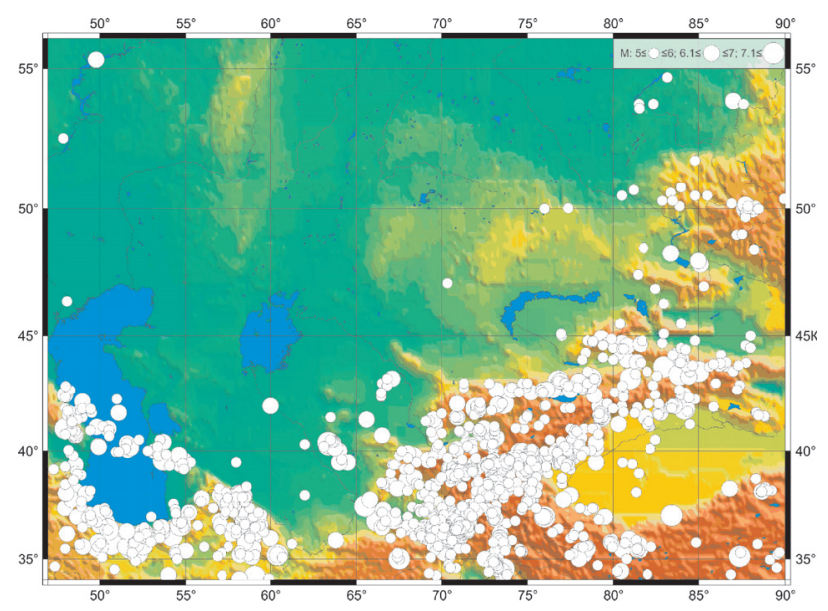

Figure 7. The map of the epicenters of large earthquakes of Central Asia with $\mathrm{M} \geq 5$ (from 2000 B.C. to 2009 A.D.).
The earthquake magnitude in the catalogues compiled in the USSR is MLH $=8.2$ [Kondorskaya and Shebalin 1977], and maximum MSK-64 intensity at the epicenter reached 10-11. The distance between the epicenter locations in the Central Asia catalogue and ISC-GEM is 133 $\mathrm{km}$, being the epicenter in GEM shifted eastward. Furthermore, the moment magnitude listed in ISC-GEM catalogue $\mathrm{Mw}=7.7$. As result of the collaboration between ISC and the Institute of Geophysical Researches (KNDC), new information about Kemin earthquake was obtained. It was found, that the Kemin earthquake was recorded by 19 stations worldwide. One of the saved records from Pyulkovo station is shown in Figure 9. In 1911 the closest station to the focus and which records were saved was Tiflis seismic station (TIF) while the most distant stations were Riverview (RIV) in Australia and Apia (API) in the Samoa Islands. A set of new literary sources was considered for more detailed study of Kemin earthquake data [Chen and Molnar 1977, Abe and Noguchi 1983, Bakun and Wentworth 1997, Delvaux et al. 2001, Arrowsmith 2005, Bindi et al. 2013, Bindi et al. 2014]. The hypocenter computed using the new collected data is located eastward than it is shown in the catalogues (Table 2). Considering the evidences from the sources, we conclude that the magnitude in Soviet catalogues is, most probably, overestimated. The value $\mathrm{Mw}=7.7 \mathrm{com}-$ puted by ISC-GEM is in agreement with the Mw estimated from intensity data [Stepp 1973]. In EMCA, both the MLH from Soviet catalogues and Mw from ISCGEM are provided. In terms of locations, considering the complexity of the rupture processes and the available data, it is not possible to prove that one solution is better than the other. In EMCA, the location from the soviet catalogues, which agrees with the location from intensity data [Bindi et al. 2014], is kept. For other 19 earthquakes with large discrepancies in solutions, EMCA catalogue adopts the solutions from ISC-GEM.

\section{Completeness assessment}

Finally, some statistical features of the catalogue are evaluated such as the completeness magnitude and the Gutenberg-Richter recurrence law. The complete- 


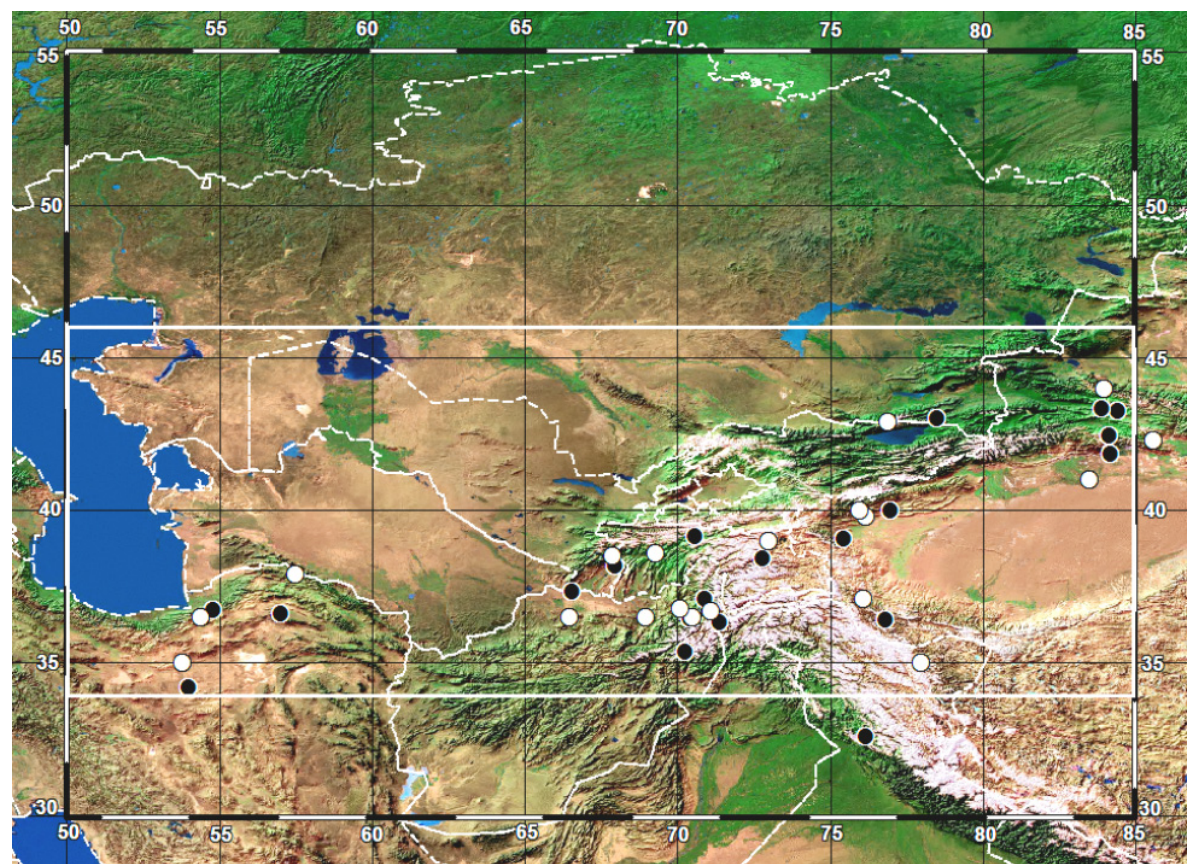

Figure 8. Earthquakes with location in ISC-GME catalogue (black) more than $40 \mathrm{~km}$ distant from the location in EMCA (white).
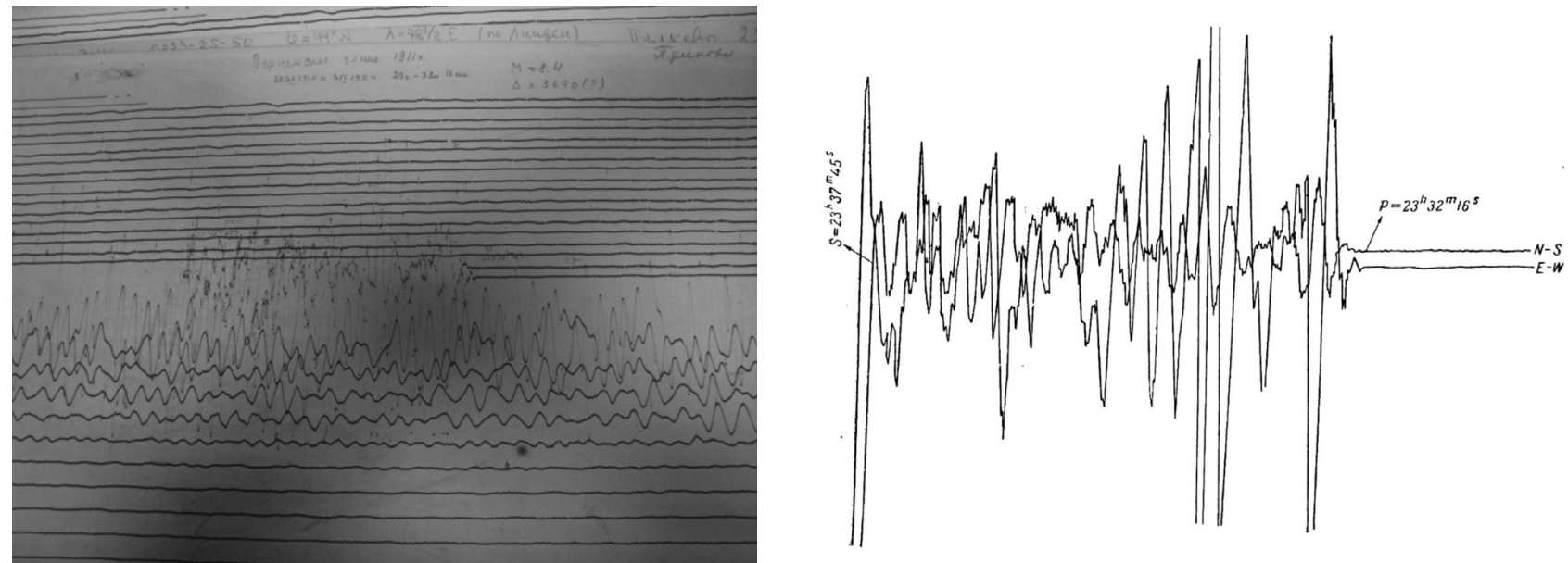

Figure 9. The record of Kemin earthquake at Pyulkovo seismic station (courtesy of Z.A. Kalmetyev).

\begin{tabular}{ccccccccc}
\multirow{2}{*}{ GEM } & Date & Time & $\varphi^{\circ}$ & $\lambda^{\circ}$ & Depth & Mw & \\
\cline { 2 - 9 } & 03.01 .1911 & $23: 25: 49.71$ & 43.01 & 78.53 & 20.0 & 7.7 & K \\
\hline \multirow{2}{*}{ EMCA } & Date & Time & $\varphi^{\circ}$ & $\varphi^{\circ}$ & Depth & MLH & 17.8
\end{tabular}

Table 2. The parameters of Kemin earthquake in ISC-GEM and EMCA catalogues.

ness magnitude (Ms) is defined as the lowest magnitude at which $100 \%$ of the earthquakes in a space-time volume have been detected. The Stepp's method [Stepp 1973 ] is used to estimate the time-completeness of different magnitude bins. It is an analytical approach based on estimators of the mean rate of recurrence of earthquakes within given magnitude and time ranges. The completeness magnitude is identified when the observed rates of earthquakes above Mc starts to deviate the expected rate. For completeness analyses, the catalogue is divided into 0.5 magnitude interval starting from magnitude 4.0. The analyses are carried out with a time interval of 5 years, using the Hazard Modelers' Toolkit provided by the GEM foundation (http: / / www.global earthquakemodel.org). The catalogue is complete from magnitude 4 starting from 1959 and from magnitude 7 starting from 1873 (Figure 10). Considering the completeness results, the recurrence Gutenberg-Richter relationship fit to data [Weichert 1980] is characterized by a b-value equal to 0.805 (Figure 11). Considering the 


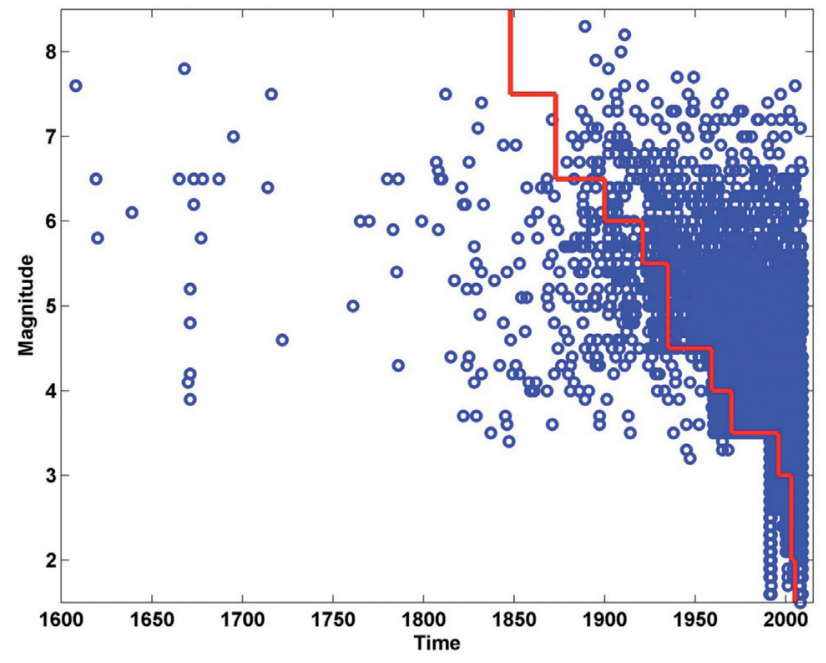

Figure 10. Completeness analysis (red line) for the EMCA catalogue (blue circle) considering MLH magnitude.

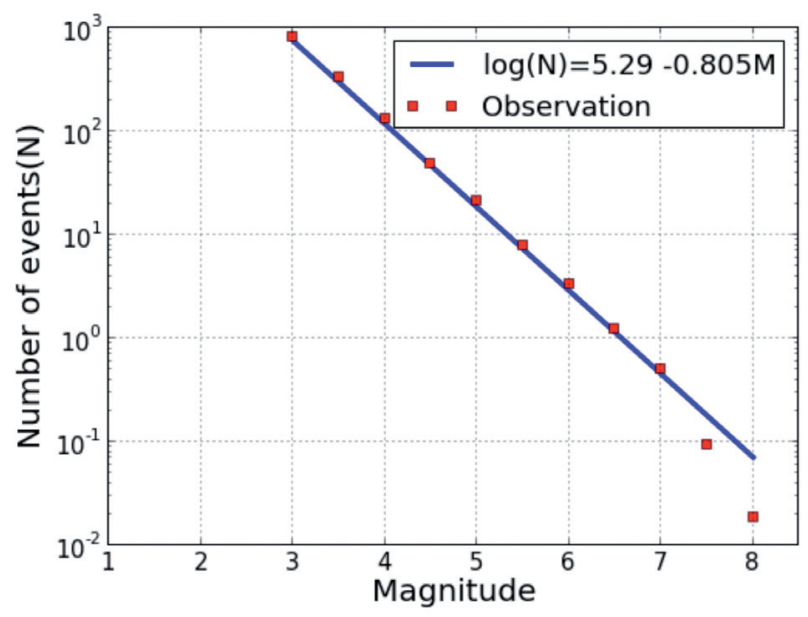

Figure 11. Gutenberg-Richter model (blue) for the EMCA catalogue considering MLH magnitude.

strong heterogeneities in the spatial distribution of earthquakes in Central Asia and the deformation occurring at different rates, the assessment of the b-value at a regional scale is of interest only for describing some statistical feature of the catalogue. A regionalization of $b$-values can be found in the article presenting the results about the hazard assessment in Central Asia obtained in the framework of EMCA [Ullah et al. 2015, this issue].

\section{Conclusions}

We presented the EMCA catalogue for seismic hazard assessment in Central Asia. The catalogue includes about 33034 earthquakes occurred in Central Asia (Kazakhstan, Kyrgyzstan, Tajikistan, Uzbekistan, Turkmenistan) from 2000 B.C. to 2009 A.D., in the MLH magnitude range from 1.5 to 8.3. If available, the catalogue contains different magnitude classes, such as MLH, mb, MS, and the energy-class K [Ullah et al. 2015, this issue]. The regression analysis performed to associate a MLH value to each entry, as well as the moment magnitude $\mathrm{Mw}$, is the subject of an article under preparation.

Acknowledgements. A fragment of this catalogue for determined territory of Central Asia and adjacent territory was kindly provided to us by the staff of the Institute of Physics of the Earth of Russian Academy of Science within the CASRI Project. Comments and suggestions provided by D. Di Giacomo are strongly acknowledged.

\section{References}

Abe, K., and S. Noguchi (1983). Determination of magnitude for large shallow earthquakes 1898-1917, Phys. Earth Planet. Int., 32, 45-59.

Arrowsmith, J.R., C.J. Crosby, A.M. Korjenkov, E. Mamyrov and I. Povolotskaya (2005). Surface rupture of the 1911 Kebin (Chon-Kemin) earthquake, Northern Tien Shan, Kyrgyzstan, Eos Trans, Book of Abstracts AGU, 86 (52), Fall Meeting, 64-68.

Bakun, W. ., and C.M. Wentworth (1997). Estimating earthquake location and magnitude from seismic intensity data, B. Seismol. Soc. Am., 87, 1502-1521.

Bindi, D., A.A. Gomez Capera, S. Parolai, K. Abdrakhmatov, M. Stucchi and J. Zschau (2013). Location and magnitudes of earthquakes in Central Asia from seismic intensity data: model calibration and validation, Geophys. J. Int., 192 (2), 710-724.

Bindi, D., S. Parolai, A. Gómez-Capera, M. Locati, Z. Kalmetyeva and N. Mikhailova (2014). Locations and magnitudes of earthquakes in Central Asia from seismic intensity data, J. Seismol., 18 (1), 1-21; doi:10. 1007/s10950-013-9392-1.

Bondár, I., E.R. Engdahl, A. Villaseñor , J. Harris and D.A. Storchak (2015). ISC-GEM: Global Instrumental Earthquake Catalogue (1900-2009): II. Location and seismicity patterns, Phys. Earth Planet. Int., 239, 2-13; doi:10.1016/j.pepi.2014.06.002.

Bormann, P. (2002). Magnitude of seismic events, In: P. Bormann (ed.), IASPEI New Manual of Seimological Observatory Practice, GeoForschungsZentrum, Potsdam, 1, 16-50.

Bragin, V.D. (2007). The Kyrgyz Seismic Network (KNET), Book of Abstracts, Spring Meeting, American Geophysical Union, 42-46.

Bulletin of the Data Center (KNDC) of RSE IGR; http: //www.kndc.kz/index.php/ru/sejsmicheskie-byul leteni/interactive-bulletin.

Bulletin of the International Seismological Center; http: //www.isc.ac.uk/iscbulletin/search/catalogue/.

Catalogue of Kyrgyzstan earthquakes, Institute of Seismology NAS KR; http:/ /www.seismo.kg/.

Chen, W-P., and P. Molnar (1977). Seismic moments of major earthquakes and the average rate of slip in Asia, J. Geophys. Res., 2945-2969. 
Consortium of the USA Universities (IRIS); http: / / ww w.iris.edu.

Delvaux, D., K.E. Abdrakhmatov, I.N. Lemzin and A.L. Strom (2001). Landslides and surface breaks of the 1911 Ms 8.2 Kemin earthquake Kyrgyzstan, Russian Geology and Geophysics, 42, 1167-1177.

Earthquakes in the USSR (1961-1991). Earthquakes in the USSR, Collection, edited by N.V. Kondorskaya, Moscow, JIPE RAS.

Earthquakes of Northern Eurasia (1991-2007). Earthquakes of Northern Eurasia, Collection, edited by O.Ye. Starovoit, Obninsk, Geophysical Survey RAS.

Inland Earthquake (1997). Inland Earthquake, Beijing, vol. 11, 183 pp.

Kondorskaya, N.V., and N.V. Shebalin (1977). New catalogue of the largest earthquakes on the territory of the USSR from ancient time to 1975, Institute of Physics of the Earth named after O.Yu. Schmidt, Moscow, JIPE, 534 pp.

Kondorskaya, N.V., and V.I. Ulomov (1996). Specialized earthquake catalogue for seismic zoning of Northern Eurasia, Main achievements of the Joint Institute of Physics of the Earth named after O.Yu. Schmidt for 1992-1996, Moscow, JIPE, 1, 108-109.

Mikhailova, N.N., and N.P. Neverova (1986). Calibration function $\sigma(\Delta)$ to determine MPVA of Northern Tien Shan earthquakes, Integrated investigations at AlmaAta prediction sitel, Alma-Ata, Science, 41-47.

Rautian, T.G. (1960). The energy of earthquakes, In: Methods of Detailed Study of Seismicity, Trudy Inst. Phys. Earth, Moscow Nauka, 176, 75-114.

Rautian, T.G. (1964). On the estimation of earthquake energy at distances up to $3000 \mathrm{~km}$, Trudy Inst. Phys. Earth, Moscow Nauka, 32, 88-93.

Rautian, T.G., and V.I. Khalturin (1994). The multi-factor model of magnitude residuals and the problem of the precise determination of magnitude, Scientific report 4, Phillips laboratory, Columbia University, New York.

Rautian, T.G., V.I. Khalturin, K. Fujita, K.G. Mackey and A.D. Kendall (2007). Origins and methodology of the russian energy $\mathrm{k}$-class system and its relationship to magnitude scales, Seismol. Res Lett., 78, 579-590.

Reviewed Event Bulletin of the International Data Center REB (IDC CTBT); http: / / www.ctbto.org/veri fication-regime/the-international-data-centre/.

Seismic Bulletin of Geological Survey of the USA (NEIC); http: / / earthquake.usgs.gov/regional/neic/ neic_bulletins.php.

Seismic Risk Assessment in Central Asia (2009). Seismic Risk Assessment in Central Asia: final project activity report on the work performed from 02.01.2006 to
04.30.2009, Institute of Geophysical Researches NNC RK, Project submanager N.N. Mikhailova, 46 pp. Seismological Experience-Methodical Expedition of MES RK; http: / /www.some.kz/.

Stepp, J.C. (1973). Analysis of completeness of the earthquake sample in the Puget Sound area, In: S.T. Harding (ed.), Seismic zoning, NOAATech Report ERL 267-ESL30, Boulder, Col., USA.

Storchak, D.A., D. Di Giacomo, E.R. Engdahl, J. Harris, I. Bondár, W.H.K. Lee, P. Bormann and A. Villaseñor (2015). The ISC-GEM Global Instrumental Earthquake Catalogue (1900-2009): Introduction, Phys. Earth Planet. Int., 239, 48-63; doi:10.1016/j.pe pi.2014.06.009.

Ullah, S., D. Bindi, M. Pilz, L. Danciu, G. Weatherill, E. Zuccolo, A. Ischuk, N.N. Mikhailova, K. Abdrakhmatov and S. Parolai (2015). Probabilistic seismic hazard assessment for Central Asia, Annals of Geophysics, 58 (1), S0103; doi:10.4401/ag-6687.

Ulomov, V.I., and L.S. Shyumilina (2000). A set of maps of general seismic zoning of the Russian Federation territory, GSZ - 97, Scale 1:8000000, Explanatory note and list of cities and settlements located at seismically active regions, The map on 4 sheets, edited by V.N. Strakhov and V.I. Ulomov, Moscow, 57 pp.

Weichert, D.H. (1980). Estimation of earthquake recurrence parameters for unequal observation periods for different magnitudes, B. Seismol. Soc. Am., 70, 1337-1356.

\footnotetext{
${ }^{\star}$ Corresponding author: Natalya N. Mikhailova, Institute of Geophysical Researches, Committee of Atomic Energy of the Republic of Kazakhstan, Almaty, Kazakhstan; email:mikhailova@kndc.kz.

C 2015 by the Istituto Nazionale di Geofisica e Vulcanologia. All rights reserved.
} 